\title{
Peer Smoking and Smoking-related Beliefs Among College Students in Bangladesh
}

\author{
Akiko Kamimura', Zobayer Ahmmad', Mu Pye'2, Bethany Gull' \\ ${ }^{1}$ Department of Sociology, University of Utah, Salt Lake City, UT, USA; ${ }^{2}$ Department of Health, Kinesiology and Recreation, University of Utah, Salt \\ Lake City, UT, USA
}

Objectives: Smoking is a significant public health issue in Bangladesh. The purpose of this study was to examine peer smoking and smoking-related beliefs among college students in Bangladesh.

Methods: College students at two universities in Dhaka, Bangladesh participated in a self-administered survey in May and June 2017. Results: First, being a current or former smoker is associated with lower levels of beliefs among respondents that they would not smoke even with smoker friends or nervousness, and lower levels of intentions that they would not smoke, while current smokers and former smokers have different smoking-related beliefs. Second, having smoker friends is associated with lower levels of intentions that they would not smoke. Third, higher levels of normative beliefs that it is important not to smoke are associated with higher levels of beliefs that they would not smoke even with smoker friends or nervousness, higher levels of intentions that they would not smoke, and higher levels of avoidance of smoking.

Conclusions: Smoking-related beliefs and perceived norms in individuals' social networks are important components in promoting tobacco cessation in Bangladesh. But it is challenging to prevent or intervene in smoking because of the high rates of smoking in this country and the high prevalence of smokers in individuals' social networks. Future studies should examine the most effective interventions to combat smoking in high-smoking social networks, such as using mobile apps or social media, and evaluate the effectiveness of such interventions.

Key words: Peer influence, Smoking prevention, Social networks, College students, Bangladesh

\section{INTRODUCTION}

Smoking is a significant public health issue in Bangladesh. Among males aged 25 to 69 , approximately $25 \%$ of deaths are smoking-attributable [1]. In an attempt to combat the health

Received: September 20, 2017 Accepted: January 6, 2018

Corresponding author: Akiko Kamimura, PhD

Department of Sociology, University of Utah, 380 S 1530 E, Salt Lake

City, UT 84112, USA

E-mail: akiko.kamimura@utah.edu

This is an Open Access article distributed under the terms of the Creative Commons Attribution Non-Commercial License (http://creativecommons.org/licenses/bync/4.0/) which permits unrestricted non-commercial use, distribution, and reproduction in any medium, provided the original work is properly cited. problems related to high rates of smoking, in 2005, a smoking and tobacco products production, use, selling-purchasing, and advertising control law was passed by the Bangladesh National Parliament [2]. As a result of the controls put in place with this law, the prevalence of smoking among adults had declined from $34.6 \%$ in 2000 to $20.0 \%$ in 2013 [3]. The law was amended in 2013 to further control smoking in public places and restrict advertisement and sales of tobacco [4]. However, the smoking prevalence is still high in Bangladesh: smoking prevalence for those ages 25 or older was $54.8 \%$ among males and 1.3\% among females in 2016 [5]. The smoking prevalence in Bangladesh is higher than the global prevalence, especially among males [6]. In fact, Bangladesh is in the top 10 rates of 
smoking in the world. Male youths ages 13-15 had 13.2\% smoking prevalence in 2016 [5]. Smoking prevalence is even higher among college students- $68.81 \%$ among male students and $19.56 \%$ among female students, according to a study conducted in Dhaka, Bangladesh [7]. Due to the high smoking prevalence and lack of effective tobacco control policies, exposure to tobacco smoke at home and in work and public places is very high and bears health risks even for non-smokers [8].

Health behaviors such as smoking are known to spread in social networks [9]. Peer smoking is one of the most significant predictors of smoking among youths and young adults [10-12]. Peer networks in which half or more members are smokers significantly increases the possibility of current smoking [10]. Peer smoking affects current and future smoking behaviors [11]. These findings that peer smoking is a significant factor for one's smoking are applicable to Bangladesh because of the high prevalence of smoking in that country [7].

In addition to social networks, smoking-related health beliefs are important predictors of smoking. In particular, smoking-related health beliefs are associated with the intention to quit smoking [13]. The theoretical background of this study is the Theory of Planned Behavior (TPB). According to the TPB, perceived disapproval of smoking from friends and family establishes a non-smoking norm and reduces the possibility of smoking among adolescents [14]. Besides perceived norms, attitude and personal-agency such as self-efficacy affects individuals' intention to smoke or not and thus their actual smoking behavior [15]. Empirical studies have proved that the TPB helps predict smoking behaviors among adolescents or young adults [16-18]. However, little is known about the reasons and sociocultural context of higher smoking rate of young adults and smoking-related health beliefs among college students in Bangladesh.

The purpose of this study was to examine peer smoking and smoking-related beliefs among college students in Bangladesh. The exploratory research based on existing knowledge and theory is guided by a research question that is: What factors affect smoking-related health beliefs among college students in Bangladesh? This study will examine whether smoking related beliefs and behaviors in individuals' social networks (independent variables) affect smoking-related beliefs (dependent variables) among college students in Bangladesh. The hypothesis of this study is as follows: Individuals embedded in social networks where smoking is common will exhibit higher levels of smoking behaviors than those whose networks have low rates of smoking. Targeting college students is important because smoking initiation during young adulthood (ages 18 to 21) is common [19]. If reducing rates of smoking is a public health goal, then knowing more about how social networks contribute to smoking beliefs and behaviors is an essential part of developing health interventions.

\section{METHODS}

\section{Data and Participants}

Data were collected using a paper self-administered survey at one public university (the University of Dhaka) and one private university (the North South University, NSU) in Dhaka, Bangladesh in May and June 2017. The University of Dhaka is the oldest and top ranked university in Bangladesh and has approximately 30000 students. The University of Dhaka offers a wide variety of academic programs. NSU has approximately 14000 students and primarily focuses on social science, humanities, business, engineering, and life sciences. These two universities were selected because these universities accept students from all social classes with diverse social backgrounds. The University of Dhaka especially has a competitive admission test processes which draw students from every part of the nation. In terms of diversity, as the NSU has higher tuition rates and fees more than the University of Dhaka, it is less likely to have students from diverse social classes. After all, the sample from the two institutions still has the diverse student body drawing from around the country. Participants were college students of one of these universities, were aged 18 years or older, and spoke and read Bengali. The survey instrument and consent cover letter were available in Bengali which is a national and official language of Bangladesh and is primarily spoken by the survey participants. The English versions of the survey instrument and consent cover letter were translated into Bengali by a bilingual translator. Another bilingual translator conducted back-translation from Bengali to English. The third bilingual translator checked the accuracy of the translation. Sampling was based on a convenience sample. Research assistants approached potential participants and distributed the consent cover letter and survey instrument in classrooms at the universities. Students who agreed to participate in the survey filled out a paper survey and returned it to a research assistant in the classroom. The consent cover letter and the survey instrument were handed to those who expressed inter- 
ests. Consent was obtained from each participant.

\section{Measures}

\section{Smoking-related self-efficacy (avoidance of smoking), beliefs and intention}

Smoking-related self-efficacy (avoidance of smoking), beliefs and intention were measured using a scale developed by Sterling and colleagues (4-point Likert scale:1, definitely yes; 4, definitely no) [20]. It has three sub-scales: 1) self-efficacy to avoid smoking (1-item: "If your friends offer you a cigarette, are you able not to smoke?"); 2) smoking-related beliefs (3-items: "If you are with friends who smoke, are you able not to smoke?," "If you feel nervous, are you able not to smoke?" and "Do you believe cigarette smoking helps people relax?"; Cronbach alpha, 0.832$) ;$ and 3) intention to continue smoking (6 items: "Do you think smoking cigarettes helps people feel more comfortable at parties and in other social situations?," "Do you think young people who smoke cigarettes have more friends?," "Do you think smoking cigarettes makes young people look cool or fit in?," "Do you think you will smoke a cigarette at any time during the next year?," "Do you think you will be smoking cigarettes 5 years from now?", and "If one of your best friends offered you a cigarette, would you smoke it?"; Cronbach alpha, 0.797$)$. Since reliability of all three items of the belief sub-scale was low, one of the items was dropped. The value of the Kaiser-Meyer Olkin measure of sampling adequacy (0.873) suggested that it would be worthwhile to conduct factor analysis. The results of factor analysis indicated that there were only two components and the sub-scale 1 (self-efficacy to avoid smoking) and the sub-scale 2 (smokingrelated beliefs) might be in the same component. Eigenvalues that are useful in determining the number of factor extractions show that component 1 had $51.86 \%$ of variance while component 2 had $13.03 \%$ of variance. However, these subscales were in the separate regression analyses and did not interact each other in the statistical model. Scoring for the belief and intention sub-scales was based on the mean of the items. Higher scores indicate lower avoidance of smoking, lower levels of not smoking even with smoker friends or nervousness, and higher levels of not continuing smoking.

\section{Beliefs related to third-hand smoking}

Beliefs related to third-hand smoking were measured using a scale, the Beliefs About Third Hand Smoke (BATHS) (5-point Likert scale: 1 , strongly disagree; 5 , strongly agree) [21]. The
BATHS contains two subscales: 1) awareness of persistence of third hand smoking (4-items: e.g., "Smoke particles can remain in a room for days."; (ronbach alpha, 0.624) and 2) awareness of health risks of third hand smoking (5-items: e.g., "Particles in rooms where people smoked yesterday can cause cancer."; Cronbach alpha, 0.742 ). Since reliability of the persistence subscale using all four items was low, one of the items was dropped to improve reliability. Scoring was based on the mean of all items in each sub-scale. Higher scores indicate higher levels of awareness of persistence or health risks of third-hand smoking.

\section{Approval of smoking by peers or parents}

Approval of smoking by peers or parents was measured using three items of the scale of normative beliefs involving smoking among adolescents (4-point Likert scale: 1, strongly disagree; 4, strongly agree) [22]. The following items were included: "According to my parents, it is very important for me to not smoke cigarettes;" "According to my friends, it is very important for me to not smoke cigarettes;" and "According to most people my age, it is very important for me to not smoke cigarettes." Scoring was based on a mean of the three items. Higher scores indicate the presence of stronger normative anti-smoking beliefs. Cronbach alpha of this study population was 0.722 .

\section{Stress}

Stress can affect smoking behaviors among college students. For example, stressful events such as exams increase the participation of smoking [23]. Stress was measured using the College Student Stress Scale which has 11 items (5-point Likert scale: 1, never; 5, very often) [24]. It asks how often a participant is distressed, anxious, or questions their abilities in a number of areas, including "personal relationships" and "academic matters." Higher scores indicate higher levels of stress. The mean score among US college students was 29.3 [24]. Cronbach alpha of this study population was 0.815 .

\section{Smoking-related participant characteristics}

The following smoking-related information was collected from participants: participant's smoking status (current, former or never), father's smoking status (current or former, or never), mother's smoking status (current or former, or never), whether a participant has a sibling who smokes, and whether a participant has friends who are smokers. 


\section{Socio-demographic characteristics}

Participants were asked the following demographic questions: age, gender, type of university they attend (public or private), year in college (for analysis-4th or 5th year at college), types of residence (living with family or not), types of home town (urban or rural), whether father has a college degree, whether mother has a college degree, and annual family income (for analysis-family income below 110000 Bangladesh taka, which is an approximate mean value among the participants, or not).

\section{Ethics Approval}

This project was approved by the institutional review board (IRB) of at a US institution. These universities in Bangladesh did not have IRBs. The IRB of the US institution has policies for international research, including those when local institutions outside the US do not have IRBs. This study followed the policies.

\section{Data Analysis}

Data were analyzed using SPSS version 22 (IBM Corp., Amok, NY, USA). Descriptive statistics were performed to describe the characteristics of participants and variables. Current smokers and former smokers were compared regarding smoking-related beliefs using independent samples $t$-tests. Multiple regression analyses were conducted to examine associations between smoking-related self-efficacy (avoidance of smoking), beliefs and intentions, and participant characteristics, beliefs related to third-hand smoking, approval of smoking by peers or parents, and stress. Multicollinearity was tested using Variance Inflation Factor. There was no significant multicollinearity issue among variables.

\section{RESULTS}

Table 1 shows the characteristics of 386 participants and descriptive statistics of variables. More than $60 \%$ of the participants were male. Respondents were split roughly in half between attendance at public and private universities. Approximately one third of the participants were current or former

Table 1. Participant characteristics

\begin{tabular}{|c|c|c|c|c|c|}
\hline Variables & Total $(\mathrm{n}=\mathbf{3 8 6})$ & Current smoker $(n=73)$ & Former smoker $(n=46)$ & $\boldsymbol{F}$ & $p$-value \\
\hline Participant current or former smoker & $119(30.8)$ & & & & \\
\hline Male & $248(64.2)$ & $71(97.3)$ & $43(93.5)$ & & NS \\
\hline Public university & $184(47.7)$ & $27(37.0)$ & $20(43.5)$ & & NS \\
\hline 4 th or 5 th year at college & $171(44.3)$ & $33(45.2)$ & $20(43.5)$ & & NS \\
\hline Living with family & $179(46.4)$ & $35(47.9)$ & $20(43.5)$ & & NS \\
\hline Urban hometown & $208(53.9)$ & $42(57.5)$ & $23(50.0)$ & & NS \\
\hline Father has a college degree & $199(51.6)$ & $44(60.3)$ & $24(52.2)$ & & NS \\
\hline Mother has a college degree & $131(33.9)$ & $32(43.8)$ & $16(34.8)$ & & NS \\
\hline Family income below 110000 BDT & $233(60.4)$ & $41(56.2)$ & $31(67.4)$ & & NS \\
\hline Father current or former smoker & 181 (46.9) & $42(57.5)$ & $25(54.3)$ & & NS \\
\hline Mother current or former smoker & $5(1.3)$ & $1(1.4)$ & $1(2.2)$ & & NS \\
\hline Sibling smoker & $128(33.2)$ & $25(34.2)$ & $13(28.3)$ & & NS \\
\hline Have friends who smoke & $323(83.7)$ & $71(97.3)$ & $43(93.5)$ & & NS \\
\hline Age (y) & $21.97 \pm 2.26$ & $22.65 \pm 2.20$ & $22.28 \pm 2.13$ & 0.10 & NS \\
\hline Avoidance of smoking & $1.69 \pm 1.06$ & $3.26 \pm 0.73$ & $1.98 \pm 0.89$ & 1.90 & $<0.01$ \\
\hline Beliefs & $1.68 \pm 0.96$ & $3.23 \pm 0.64$ & $1.76 \pm 0.70$ & 0.24 & $<0.01$ \\
\hline Intention & $3.17 \pm 0.71$ & $2.20 \pm 0.63$ & $3.11 \pm 0.58$ & 0.56 & $<0.01$ \\
\hline Third hand smoking: persistence & $2.95 \pm 0.66$ & $2.65 \pm 0.77$ & $2.84 \pm 0.65$ & 1.23 & NS \\
\hline Third hand smoking: health risks & $3.33 \pm 0.69$ & $3.03 \pm 0.75$ & $3.18 \pm 0.74$ & 0.02 & NS \\
\hline Approval & $3.44 \pm 0.56$ & $3.16 \pm 0.60$ & $3.39 \pm 0.48$ & 2.77 & $<0.05$ \\
\hline Stress & $30.43 \pm 7.52$ & $30.33 \pm 7.13$ & $30.50 \pm 6.91$ & 0.004 & NS \\
\hline
\end{tabular}

Values are presented as number (\%) or mean \pm standard deviation.

Categorical variables: $p$-values are from chi-square tests; Continuous variables: $F$ and $p$-values are from independent samples $t$-tests.

BDT, Bangladeshi taka; NS, not significant. 
Table 2. Predictors of continuity of smoking-related self-efficacy ( $N=386)$

\begin{tabular}{|c|c|c|c|c|c|c|}
\hline \multirow{2}{*}{ Variables } & \multicolumn{2}{|c|}{ Avoidance } & \multicolumn{2}{|c|}{ Beliefs } & \multicolumn{2}{|c|}{ Intention } \\
\hline & $\beta$ & $p$-value & $\beta$ & $p$-value & $\boldsymbol{\beta}$ & $p$-value \\
\hline Age (y) & -0.02 & NS & -0.01 & NS & 0.002 & NS \\
\hline Male & 0.04 & NS & 0.12 & NS & 0.23 & NS \\
\hline Public university & 0.03 & NS & -0.11 & NS & 0.12 & NS \\
\hline Living with family & -0.05 & NS & -0.08 & NS & 0.02 & NS \\
\hline 4th or 5th year in college & 0.05 & NS & -0.01 & NS & -0.02 & NS \\
\hline Family income below 110000 BDT & 0.05 & NS & 0.004 & NS & 0.02 & NS \\
\hline Home town in urban & -0.02 & NS & 0.02 & NS & -0.07 & NS \\
\hline Father has college degree & 0.15 & NS & -0.05 & NS & 0.03 & NS \\
\hline Mother has college degree & -0.08 & NS & -0.06 & NS & 0.16 & $<0.05$ \\
\hline Current smoker & 2.00 & $<0.01$ & 1.87 & $<0.01$ & -1.08 & $<0.01$ \\
\hline Former smoker & 0.85 & $<0.01$ & 0.46 & $<0.01$ & -0.30 & $<0.01$ \\
\hline Father current or former smoker & -0.09 & NS & 0.05 & NS & 0.06 & NS \\
\hline Sibling smoker & -0.02 & NS & -0.08 & NS & -0.001 & NS \\
\hline Friend smoker & 0.11 & NS & 0.05 & NS & -0.24 & NS \\
\hline Approval & -0.19 & $<0.05$ & -0.21 & $<0.01$ & 0.21 & $<0.01$ \\
\hline Stress & 0.01 & NS & 0.01 & NS & -0.004 & NS \\
\hline (Constant) & 1.85 & $<0.01$ & 2.15 & $<0.01$ & 2.83 & $<0.01$ \\
\hline$R^{2}$ & 0.63 & & 0.69 & & 0.51 & \\
\hline$F$ & 30.14 & & 37.89 & & 17.37 & \\
\hline$p$-value & $<0.01$ & & $<0.01$ & & $<0.01$ & \\
\hline
\end{tabular}

$p$-value denotes significance from multivariate regression analysis.

NS, not significant; BDT, Bangladeshi taka.

smokers ( $n=119,30.8 \%$ ), though the percentage was very different between males and females. Among male participants, $46 \%$ were current or former smokers. However, among female participants, only $3.6 \%$ were current or former smokers. While nearly half of the participants' fathers were ever smokers $(46.9 \%)$, only $1.3 \%$ of their mothers were ever smokers. One third of the participants had at least one sibling who smoked (33.2\%). More than $80 \%$ of the participants had friends who were smokers (83.7\%).

Table 1 also presents the comparison between current and former smokers in smoking-related beliefs. There was no significant difference in demographic characteristics between the two groups. Current smokers reported lower levels of avoidance of smoking $(p<0.01)$, lower levels of not smoking with smoker friends or nervousness $(p<0.01)$, lower levels of intention of not smoking $(p<0.01)$, and lower levels of perceived norms of not smoking from friends or family $(p<0.05)$.

Table 2 describes the results of regression analyses. If a participant's mother had a college degree, he/she had higher levels of intention of not smoking $(p<0.05)$. Both current and former smokers reported lower levels of avoidance of smoking, lower levels of beliefs that they would not smoke even with smoker friends or nervousness, and lower levels of intention of not smoking $(p<0.01)$. Higher levels of disapproval of smoking from friends or family were associated with higher levels of avoidance of smoking $(p<0.05)$, higher levels of beliefs that they would not smoke even with smoker friends or nervousness $(p<0.01)$, and higher levels of intention of not smoking $(p<0.01)$. Since the results of the factor analysis suggest avoidance and beliefs may be in the same component, it is not surprising that the results for these dependent variables are similar to each other. The only difference is that the association between approval and avoidance was at the 0.05 significance level while the association between approval and beliefs was at the 0.01 significance level.

\section{DISCUSSION}

This study examined the association between smoking beliefs and behaviors in individuals' social networks and smoking-related beliefs among college students in Bangladesh. Three main findings emerged from the data. First, being a cur- 
rent or former smoker is associated with lower levels of beliefs that respondents would not smoke even with smoker friends or nervousness, and lower levels of intentions that they would not smoke, while current smokers and former smokers have different smoking-related beliefs. Second, having smoker friends and family is associated with lower levels of intentions that respondents would not smoke. Third, higher levels of normative beliefs that it is important not to smoke are associated with higher levels of beliefs that they would not smoke even with smoker friends and family or nervousness, higher levels of intentions that they would not smoke, and higher levels of avoidance of smoking.

Participants who were current or former smokers were more likely to report lower levels of beliefs that they would not smoke even with smoker friends or nervousness, and lower levels of intentions that they would not smoke compared to those who had never smoked. Smoking-related beliefs are associated with smoking cessation before and/or after. The World Health Organization recommends tobacco control strategies for governments which focus on public health, health systems and surveillance and information [25]. Further research on former smokers and their smoking-related beliefs and tobacco avoidance strategies may help to develop effective smoking cessation programs in Bangladesh and other low resource countries.

The results that a person is less likely to have intentions of not smoking if friends smoke indicate that peer smoking is a significant factor that affects smoking. The results are consistent with previous studies that showed the impact of social networks on smoking [10-12]. Reducing influence from friends and the popularity of smokers in the social networks can decrease the prevalence of smoking [26]. It is very important to develop non-smoker social networks. Future studies should develop strategies of how to support non-smokers in social networks containing smokers as well as how to build and maintain social networks of non-smokers in an environment with a high smoking prevalence.

Furthermore, the results of this study suggest that whether smoking is approved or disapproved by peers or parents is an important factor for smoking behaviors. The results are consistent with the TPB [13] and previous studies conducted in other Asian countries such as Thailand [27] and Vietnam [28]. Since more than $80 \%$ of the participants had friends who were smokers, it is possible that most social groups among college students in Bangladesh have smokers. Non-smokers, especial- ly male non-smokers, may be "minorities" in some social groups. Further studies should examine how smoking status (current, former or never smoker) affects membership and status in social groups as well as their health outcomes.

While this study provides the information about smokingrelated beliefs among college students in Bangladesh, there are limitations. This study is cross-sectional and is unable to determine causal directions among variables. The data were collected in two universities in Bangladesh. The degree to which the results can be generalized is limited. There is a possibility that the sample was skewed because this study used a convenience sample. For example, students who were interested in smoking-related issues might be more likely to have participated in this study. Furthermore, an actual response rate is not known due to convenience sampling. There are some potential confounding variables such as the quantity of daily smoking, and smoking duration. In addition, the population surveyed, college students, represents a small percentage of the Bangladeshi population. Future research should expand exploration of smoking-related beliefs and behaviors into other socioeconomic groups as well as among subjects in different age categories. This study used a scale developed outside of Bangladesh. Some of the items were dropped from the original scales to increase reliability. The key scale that measured smoking-related self-efficacy (avoidance of smoking), beliefs and intention was originally developed to have three sub-scales. But among the participants of this study, it was possible that there are only two components.

Smoking-related beliefs, social network and perceived norms through friends are important components to promote tobacco cessation in Bangladesh. Using mobile phone apps specifically designed as smoking interventions may be one of the ways to provide interventions to college students who are in a smoker social network [29]. Interventions using social media such as Facebook or Twitter are found acceptable and effective in the US and may also show efficacy in a Bangladeshi setting [30], because social media is becoming popular among college students in Bangladesh [31]. Due to a high smoking rate in Bangladesh, college students have lots of ties with smokers. Future studies should develop interventions that may overcome a smoker social network peer influences and evaluate the effectiveness of such interventions. Furthermore, future studies should focus on developing intervention strategies that would target peer networks and peer influences on higher prevalence of smoking. 


\section{ACKNOWLEDGEMENTS}

We thank participants of this study and Abdullah Al-Hossain, Nazmun Nahar, Ujal Ibrahim, Sharmin Ahmed, and Kai Sin for their help in data collection or entry.

\section{CONFLICT OF INTEREST}

The authors have no conflicts of interest associated with the material presented in this paper.

\section{ORCID}

\section{Akiko Kamimura https://orcid.org/0000-0001-6528-5770 \\ Bethany Gull https://orcid.org/0000-0002-3422-0103}

\section{REFERENCES}

1. Alam DS, Jha P, Ramasundarahettige C, Streatfield PK, Niessen LW, Chowdhury MA, et al. Smoking-attributable mortality in Bangladesh: proportional mortality study. Bull World Health Organ 2013;91(10):757-764.

2. Bangladesh National Parliament. Smoking and tobacco products production, use, selling-purchasing, and advertising control law; 2005 [cited 2017 Nov 9]. Available from: http://apps. who.int/fctc/implementation/database/sites/implementation/files/documents/reports/bangladesh_annex2_tobacco_ control_law_2005.pdf?ua =1.

3. World Health Organization. Tobacco control in Bangladesh: 2015 [cited 2017 Nov 9]. Available from: http://www.who.int/ tobacco/about/partners/bloomberg/bgd/en/.

4. World Health Organization. Bangladesh: national tobacco control law amended [cited 2017 Nov 9]. Available from: http:// www.who.int/fctc/implementation/news/news_ban/en/.

5. World Health Organization. WHO report on the global tobacco epidemic, 2017. Country profile: Bangladesh [cited 2017 Sep 19]. Available from: http://who.int/tobacco/surveillance / policy/country_profile/bgd.pdf?ua $=1$.

6. World Health Organization. Global Adult Tobacco Survey (GATS). Fact sheet Bangladesh: 2009 [cited 2017 Nov 9]. Available from: http://www.who.int/tobacco/surveillance/fact_sheet_ of_gats_bangladesh_2009.pdf.

7. Hossain S, Hossain S, Ahmed F, Islam R, Sikder T, Rahman A. Prevalence of tobacco smoking and factors associated with the initiation of smoking among university students in Dhaka,
Bangladesh. Cent Asian J Glob Health 2017;6(1):244.

8. Palipudi KM, Sinha DN, Choudhury S, Mustafa Z, Andes L, Asma S. Exposure to tobacco smoke among adults in Bangladesh. Indian J Public Health 2011;55(3):210-219.

9. Smith KP, Christakis NA. Social networks and health. Annu Rev Sociol 2008;34:405-429.

10. Alexander C, Piazza M, Mekos D, Valente T. Peers, schools, and adolescent cigarette smoking. J Adolesc Health 2001;29(1): 22-30.

11. Hall JA, Valente TW. Adolescent smoking networks: the effects of influence and selection on future smoking. Addict Behav 2007;32(12):3054-3059.

12. Powell LM, Tauras JA, Ross H. The importance of peer effects, cigarette prices and tobacco control policies for youth smoking behavior. J Health Econ 2005;24(5):950-968.

13. Radtke T, Scholz U, Keller R, Hornung R. Smoking is ok as long as I eat healthily: compensatory Health Beliefs and their role for intentions and smoking within the Health Action Process Approach. Psychol Health 2012;27 Suppl 2:91-107.

14. Collins RL, Ellickson PL. Integrating four theories of adolescent smoking. Subst Use Misuse 2004;39(2):179-209.

15. Montano DE, Kasprzyk D. Theory of reasoned action, theory of planned behavior, and the integrated behavioral model. In: Glanz K, Rimer BK, Viswanath K, editors. Health behavior and health education: theory, research, and practice. 4th ed. San Francisco: Jossey-Bass; 2008, p. 67-96.

16. Higgins A, Conner M. Understanding adolescent smoking: the role of the theory of planned behaviour and implementation intentions. Psychol Health Med 2003;8(2):173-186.

17. McMillan B, Conner M. Using the theory of planned behaviour to understand alcohol and tobacco use in students. Psychol Health Med 2003;8(3):317-328.

18. Wilkinson D, Abraham C. Constructing an integrated model of the antecedents of adolescent smoking. Br J Health Psychol 2004;9(Pt 3):315-333.

19. Bernat DH, Klein EG, Forster JL. Smoking initiation during young adulthood: a longitudinal study of a population-based cohort. J Adolesc Health 2012;51(5):497-502.

20. Landrum Sterling K, Diamond PM, Dolan Mullen P, Pallonen U, Ford KH, McAlister AL. Smoking-related self-efficacy, beliefs, and intention: assessing factorial validity and structural relationships in 9th-12th grade current smokers. Addict Behav 2007:32(9):1863-1876.

21. Haardörfer R, Berg CJ, Escoffery C, Bundy $Ł T$, Hovell M, Kegler MC. Development of a scale assessing Beliefs About Third- 
Hand Smoke (BATHS). Tob Induc Dis 2017;15:4.

22. Primack BA, Switzer GE, Dalton MA. Improving measurement of normative beliefs involving smoking among adolescents. Arch Pediatr Adolesc Med 2007;161(5):434-439.

23. Nichter M, Nichter M, Carkoglu A; Tobacco Etiology Research Network. Reconsidering stress and smoking: a qualitative study among college students. Tob Control 2007;16(3):211214.

24. Feldt RC. Development of a brief measure of college stress: the college student stress scale. Psychol Rep 2008;102(3):855860.

25. World Health Organization. Policy recommendations for smoking cessation and treatment of tobacco dependence [cited 2017 Sep 19]. Available from: http://www.who.int/tobacco/ publications/smoking_cessation/recommendations/en/.

26. Schaefer DR, Adams J, Haas SA. Social networks and smoking: exploring the effects of peer influence and smoker popularity through simulations. Health Educ Behav 2013;40(1 Suppl):
24S-32S.

27. Page RM, Suwanteerangkul J, Sloan A, Kironde J, West J. Thai adolescents' normative beliefs of the popularity of smoking among peers, adults, the successful and elite, and parents. Soc Dev 2012;21(4):849-867.

28. Page RM, Huong NT, Chi HK, Tien TQ. Social normative beliefs about smoking among Vietnamese adolescents. Asia Pac J Public Health 2012;24(1):68-81.

29. Brinker TJ, Seeger W, Buslaff F. Photoaging mobile apps in school-based tobacco prevention: the mirroring approach. J Med Internet Res 2016;18(6):e183.

30. Naslund JA, Kim SJ, Aschbrenner KA, McCulloch LJ, Brunette MF, Dallery J, et al. Systematic review of social media interventions for smoking cessation. Addict Behav 2017;73:81-93.

31. Jahan I, Ahmed SZ. Students' perceptions of academic use of social networking sites: a survey of university students in Bangladesh. Inf Dev 2012;28(3):235-247. 